Supplement of Solid Earth, 10, 1541-1554, 2019

https://doi.org/10.5194/se-10-1541-2019-supplement

(C) Author(s) 2019. This work is distributed under

the Creative Commons Attribution 4.0 License.

(c) (i)

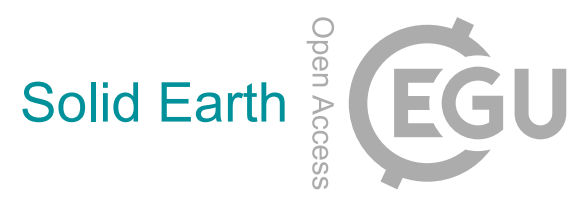

Supplement of

\title{
Can anaerobic oxidation of methane prevent seafloor gas escape in a warming climate?
}

\section{Christian Stranne et al.}

Correspondence to: Christian Stranne (christian.stranne@geo.su.se)

The copyright of individual parts of the supplement might differ from the CC BY 4.0 License. 


\section{Supplementary Information}

\section{Sensitivity of SRZ depth}

The sensitivity of our results to changes in SRZ depth was investigated by adding two sets of model simulations; Case B1 with an SRZ depth equal to $2.5 \mathrm{~m}$ (default value is $5 \mathrm{~m}$ ) and Case B2 with an SRZ depth equal to $7.5 \mathrm{~m}$. The AOM rate is kept at $10^{-8} \mathrm{~mol} \mathrm{~cm}^{-3}$ day $^{-1}$ (corresponding to Case A4). The interpretation of these results are far from straight forward, because when the SRZ depth is changed, it influences several parameters. Clearly, when increasing the SRZ depth, the AOM capacity increases which should make the microbial filter more effective, but the initial hydrate mass is also altered which affects the amount of over pressure that builds up within the sediments. This in turn effects the vertical $\mathrm{CH}_{4}$ transport in both low permeability sediments (through hydraulic fracture dynamics) and high permeability sediments (through Darcy's law). Also the travel distance from the dissociation front to the seafloor changes, which affects the timing of seafloor $\mathrm{CH}_{4}$ release. It is a complex task to separate these different aspects from the AOM dynamics and therefore, we discuss only the net effect of variations in SRZ depth below. 

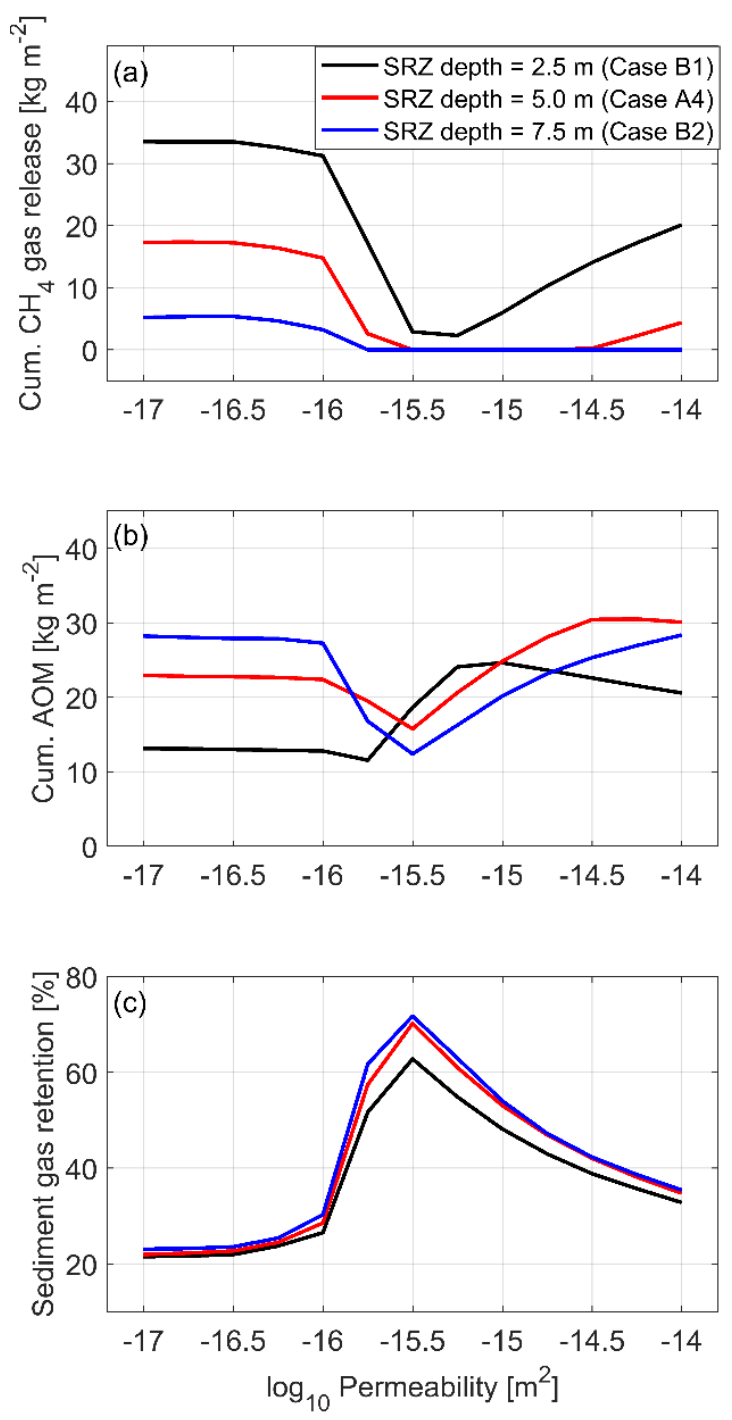

Figure S1. Sensitivity of the results to changes in SRZ depth. All data are from 200 years into the simulations.

In terms of $\mathrm{CH}_{4}$ gas escape from the seafloor (Fig. S1a) the trend is quite clear, with fluxes decreasing with increasing SRZ depth. For Case B2 gas is only escaping in the fracture flow regime, and the cumulative mass flux is fairly low ( $\sim \mathrm{kg} \mathrm{CH}_{4} \mathrm{~m}^{-2}$ ). In terms of cumulative AOM quantities, the picture is a bit more complex. The clear minimum seen for mid-permeability sediments is not present in the B1 Case. Instead, there is a peak in cumulative AOM for sediments with a permeability of $10^{-15} \mathrm{~m}^{2}$. This is presumably because, with the reduced AOM capacity the microbial filter is most efficient when $\mathrm{CH}_{4}$ percolates slowly through the SRZ, while higher $\mathrm{CH}_{4}$ transport only leads to more gas escaping the microbial filter. The sediment gas retention (Fig. S1c) is surprisingly unresponsive to changes in SRZ depth. The amount of gas still residing within the sediments seems to be a function of the sediment transport capacity alone - if the 
$\mathrm{CH}_{4}$ supplied to the SRZ ends up in the AOM pool or in the ocean is another matter (larger SRZ depth leads to a more effective microbial filter as discussed above).

\section{Sensitivity of Sh}

The sensitivity of our results to changes in $S_{h}$ was investigated by adding two sets of model simulations; Case C1 with $S_{h}$ equal to 2.5\% (default value is 5\%) and Case C2 with $S_{h}$ equal to $7.5 \%$. The AOM rate is kept at $10^{-8} \mathrm{~mol} \mathrm{~cm}^{-3}$ day $^{-1}$ (corresponding to Case A4). While the AOM capacity stays constant when changing $\mathrm{S}_{\mathrm{h}}$, the initial hydrate mass is altered which affects the amount of $\mathrm{CH}_{4}$ in the system and the amount of over pressure that builds up. This in turn effects the vertical $\mathrm{CH}_{4}$ transport in both low and high permeability sediments. The net effect of these changes is discussed below.
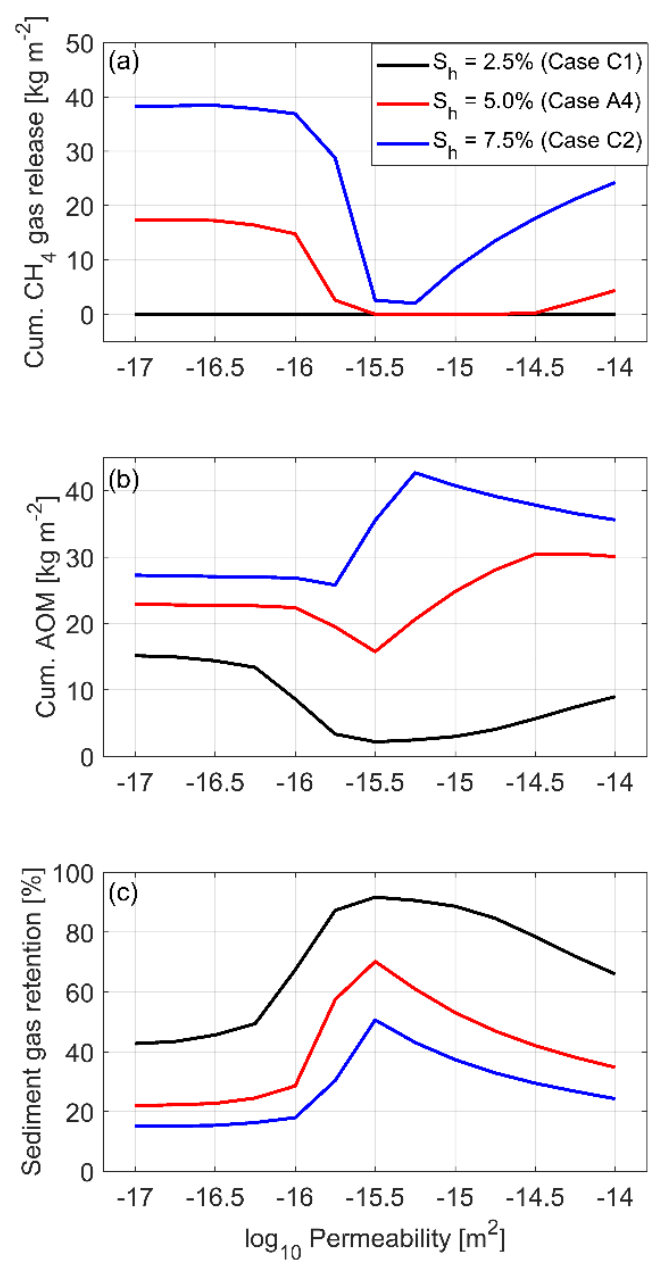

Figure S2. Sensitivity of the results to changes in initial hydrate saturation. All data are from 200 years into the simulations.

Naturally, the cumulative $\mathrm{CH}_{4}$ gas escape quantities increase with increasing Sh (Fig. S2a). The same is true for the cumulative AOM (Fig. S2b), but the picture is somewhat more complex. For Case C1, all the 
$\mathrm{CH}_{4}$ that reaches the SRZ is oxidized (as evident from the fact that no gas is escaping the sediments at any permeability, Fig S2a). Looking at Case C2, we note that it has a shape very similar to the corresponding Case B1 curve (Fig. S1b). We interpret the peak in cumulative AOM for sediments with a permeability of $10^{-15.25} \mathrm{~m}^{2}$ as a maximum in AOM efficiency, where higher $\mathrm{CH}_{4}$ transport only leads to more gas escaping the microbial filter. As already discussed, the sediment gas retention is mainly a measure of the $\mathrm{CH}_{4}$ transport capacity of sediments. Decreasing $S_{h}$ leads however to lower over-pressures building up within the sediments which leads to a less effective $\mathrm{CH}_{4}$ transport towards the seafloor and thus higher $\mathrm{CH}_{4}$ gas retention (percentage wise).
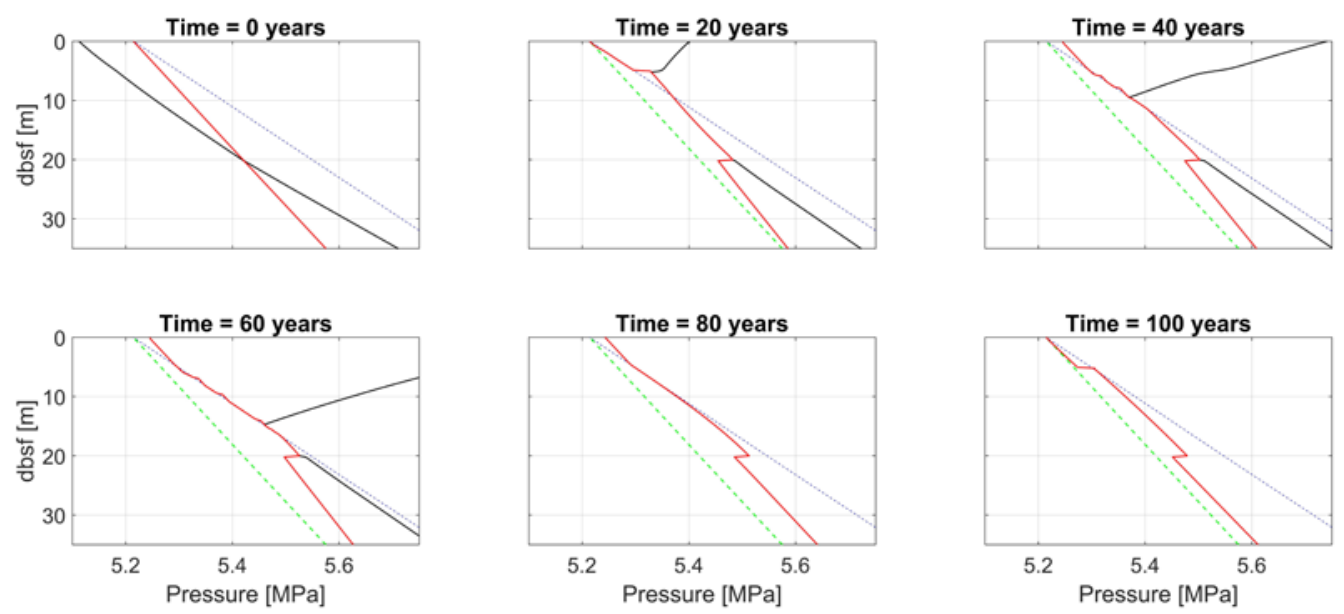

Figure S3. Pressure evolution in Case A4 with sediment intrinsic permeability of $10^{-17} \mathrm{~m}^{2}$. In situ pore pressure (red), phase transition boundary (black), initial hydrostatic pressure (dashed green), and critical pressure (dashed blue) as a function of depth at different times. Initially, the GHSZ extends to 20 mbsf as indicated by the intersection between the in situ pressure and phase transition boundary curves. Fractures start forming after 35 years, as pore pressure reaches the critical pressure, which keeps pressure from building up farther. Note the train of fractured zones approaching the seafloor at time equal to 40 and to 60 years (see Fig. 8d for another visual representation of the hydraulic fracture propagation within the sediment column). 